\title{
BMJ Open Confidence and willingness among laypersons in the UK to act in a head injury situation: a qualitative focus group study
}

\author{
Stefan Tino Kulnik (D) , ${ }^{1}$ Mary Halter, ${ }^{1}$ Ann Hilton, ${ }^{1}$ Aidan Baron, ${ }^{1}$ Stuart Garner, ${ }^{2}$ \\ Heather Jarman, ${ }^{3}$ Barry Klaassen, ${ }^{4,5}$ Emily Oliver (1) ${ }^{4}$
}

To cite: Kulnik ST, Halter M, Hilton A, et al. Confidence and willingness among laypersons in the UK to act in a head injury situation: a qualitative focus group study. BMJ Open 2019;9:e033531. doi:10.1136/ bmjopen-2019-033531

- Prepublication history and additional material for this paper are available online. To view please visit the journal (http:// dx.doi.org/10.1136/bmjopen2019-033531).

Received 09 August 2019 Revised 30 September 2019 Accepted 17 October 2019

A) Check for updates

(c) Author(s) (or their employer(s)) 2019. Re-use permitted under CC BY-NC. No commercial re-use. See rights and permissions. Published by BMJ.

${ }^{1}$ Faculty of Health, Social Care and Education, Kingston University and St George's, University of London, London, UK

${ }^{2}$ Talbot Primary School,

Bournemouth, UK

${ }^{3}$ Emergency Department, St George's University Hospitals NHS Foundation Trust, London, UK

${ }^{4}$ British Red Cross, London, UK ${ }^{5}$ Ninewells Hospital and Medical School, Dundee, UK

Correspondence to

Dr Stefan Tino Kulnik;

s.t.kulnik@sgul.kingston.ac.uk

\section{ABSTRACT}

Objectives To explore factors influencing confidence and willingness among laypersons in the UK to act in a head injury situation, in order to inform first aid education offered by the British Red Cross.

Design Qualitative focus group study.

Setting South East England.

Participants Forty-four laypersons (37 women, 7 men) were purposively recruited from the general public using snowball sampling, into one focus group each for six population groups: parents of young children $(n=8)$, informal carers of older adults $(n=7)$, school staff $(n=7)$, sports coaches $(n=2)$, young adults $(n=9)$ and 'other' adults $(n=11)$. The median (range) age group across the sample was 25-34 years (18-24, 84-95). Participants were from Asian $(n=6)$, Black $(n=6)$, Mixed $(n=2)$ and White $(n=30)$ ethnic backgrounds.

Results The majority of participants described being confident and willing to act in a head injury scenario if that meant calling for assistance, but did not feel sufficiently confident or knowledgeable to assist or make decisions in a more involved way. Individuals' confidence and willingness presented as fluid and dependent on an interplay of situational and contextual considerations, which strongly impacted decision-making: prior knowledge and experience, characteristics of the injured person, un/ observed head injury, and location and environment. These considerations may be framed as enablers or barriers to helping behaviour, impacting decision-making to the same extent as-or even more so than-the clinical signs and symptoms of head injury. An individual conceptual model is proposed to illustrate inter-relationships between these factors.

Conclusions Our findings show that confidence and willingness to act in a head injury scenario are dependent on several contextual and situational factors. It is important to address such factors, in addition to knowledge of clinical signs and symptoms, in first aid education and training to improve confidence and willingness to act.

\section{INTRODUCTION}

In the UK, the National Institute for Health and Care Excellence describes head injury as the most common cause of death and disability in children and adults under the
Strengths and limitations of this study

- The sample was a targeted but self-selected group, likely to have a personal interest in head injury, and from one geographical region in the UK.

- Purposive recruitment of sports coaches did not achieve the desired number of participants.

- Diversity in sample demographics supports the representativeness and relevance of findings.

- Involvement of different stakeholders, including representatives from the British Red Cross, National Health Service clinicians in emergency services and service users, supports the credibility of findings and analysis.

age of 40 years. ${ }^{1}$ However, only about $5 \%$ of those attending the emergency department (ED) have moderate or severe head injury, and death from head injury occurs in only $0.2 \%$ of those attending ED with a head injury. ${ }^{1}$ It is suggested that laypeople could be supported in their decision-making as first responders, in effect conducting a type of pre-triage. ${ }^{12}$ The purpose of such an approach is to provide reassurance when it is safe to self-care outside of the ED, and at the same time ensure that individuals with serious symptoms of head injury understand that they need to attend the ED urgently. Guidance for laypeople for pre-triage, (self-) assessment and early management of head injury is available, ${ }^{1}$ including which clinical signs and symptoms allow the differentiation of minor and more serious head injury and concussion. ${ }^{3}$ These guidelines appear to assume that the layperson will engage with such decision-making. However, in trauma more broadly Oliver and colleagues noted that laypeople made calls for assistance in $93 \%$ of cases, but first aid was only administered to $43 \%-57 \%$ of those alive at scene. ${ }^{4}$ Commenting on these findings, McNulty 
suggests that when a person is injured, people mostly lack the skills and confidence to do more than calling for an emergency ambulance. ${ }^{5}$

Ambiguity in decision-making is a recognised factor impacting (lay) first responder behaviour, that is, their confidence and willingness to act. ${ }^{6} \mathrm{~A}$ number of studies have explored laypersons' confidence and willingness to act in first aid scenarios, and identified that contextual and situational factors are influential in the decision whether to assist or not. For example, in an analysis of 16 million emergency services episodes in the USA, bystanders were more likely to exhibit helping behaviour when the patient was male or older; and in urban and institutional settings, as opposed to rural and public street settings. ${ }^{7}$ The type of medical emergency also influenced first aid behaviour, with bystanders more likely to take action for cardiac arrest, chest pain, allergic reaction, respiratory distress and trauma, and least likely to help for sexual assault and psychiatric disorder. ${ }^{7}$ The presence of other bystanders is understood to generally decrease the likelihood of lay responder action, a phenomenon described as 'diffusion of responsibility'. ${ }^{68}$

Previous research undertaken by the British Red Cross (BRC) and others has identified ways to overcome some of these contextual barriers to helping, ${ }^{910}$ and these findings have been embedded in all BRC first aid education. But although this evidence is based on studies which partly included trauma populations, no research has explored these contextual and situational aspects and their impact on confidence and willingness to act specific to head injury. To address this gap in evidence, this article presents findings from a research project funded by the BRC to inform their larger programme of work on first aid education and training in head injury.

This article addresses the following research questions:

- How do laypersons describe their confidence and willingness to act in response to a head injury?

- What do laypersons see as enablers and barriers to changing their own behaviour, or that of others?

- Are any differences observed between population groups of differing demographics?

\section{METHOD}

\section{Design}

This study was a qualitative inquiry using focus groups and semi-structured interviews, ${ }^{11} 12$ nested within a larger pragmatic mixed methods study. ${ }^{13} 14$

\section{Participants and recruitment}

Recruitment was purposive, aiming to recruit participants from six self-defined population groups. These groups were targeted because of their differing perspectives and experiences of head injury: parents of young children (babies and toddlers), informal carers of older adults (self-identification as informal carer), school staff (employed teacher or teaching assistant), sports coaches (including professional and amateur sports), young adults (age 18-24 years) and 'other' adults. It was recognised that participants might identify with more than one group, and participants were guided to focus primarily on their experiences within the group they were recruited to. Participants remained eligible if they had prior first aid training for lay responders, but were excluded if they were qualified or trainee healthcare professionals.

Participants were recruited by snowball sampling. ${ }^{12}$ The researchers approached suitable lead contacts, for example a health visitor at a children's centre, a sheltered housing warden, a cycling coach and a university lecturer. The researchers and/or initial lead contacts provided eligible individuals with participant information sheets (including researchers' contact details) and consent forms. Individuals expressed their interest in the study by contacting the research team directly. All participants gave written informed consent to take part in the research. They were asked to circulate study information to other potential participants within their social and/or professional networks. To facilitate recruitment, focus group or interview times and venues were arranged at participants' convenience, for example at their usual work or meeting place, and a shopping voucher was offered as compensation for participants' time and to cover any travel expenses. Childcare and carer costs were also offered where appropriate. Where participants could not practicably be formed into an in-person or virtual focus group, an individual face to face or telephone interview was offered.

\section{Data collection}

Focus groups were held in two stages within each population group, using semi-structured topic guides. ${ }^{11}$ Topic guides were designed with project stakeholders, including the service user representative on the study team (AH). At the first stage, focus groups explored the meaning of head injury, participants' understanding of its signs and symptoms, and their confidence and willingness to act in response to a head injury. In the second focus group, materials to guide lay decision-making regarding action following head injury were introduced, with the aim of prompting further discussion about confidence and willingness to act when applied to hypothetical scenarios. Example questions to the groups included What does 'head injury' mean to you? and What is your understanding of what to do when somebody has a head injury? The complete topic guide is available in online supplement 1.

All focus groups were moderated by an experienced researcher $(\mathrm{MH})$ and co-moderated by one or two other members of the research team (AB, AH, STK), who supported logistics, observed interpersonal group dynamics, took concurrent field notes (speaker order, non-verbal cues, reflective notes) and/or led in moderating parts of the discussion.

\section{Data analysis}

Focus groups were digitally audio recorded and transcribed verbatim by a professional transcription service. Transcripts were checked for accuracy against recordings by members of the research team and individual speakers were assigned unique pseudonyms, for example, 'F1' or 'M2' denoting a female or male speaker, respectively. 
Analysis of transcripts and field notes was by framework analysis. ${ }^{15}$ Two researchers (MH, STK) read and re-read the transcripts and through discussion developed a coding framework, iterated further by a third researcher (AB) involved in the focus group data collection. Coding was carried out using NVivo11 software (QSR International, 2017). Themes were developed iteratively in discussion with the group of three researchers who also extracted illustrative direct quotes, within the framework of the population groups. Researcher reflexivity was enacted through open discussion in the group of researchers and with stakeholders, providing a forum to address and resolve alternative viewpoints, challenges and criticisms. In a final analysis step, the framework was developed into a conceptual model which crossed population groups.

\section{Patient and public involvement}

A service user representative (AH) was part of the study team and contributed to the study design, data collection, study oversight and the dissemination of findings.

\section{RESULTS}

\section{Participants}

Forty-four participants from the six population groups took part. In the sports coach group, only two participants could be recruited and were interviewed individually rather than in a focus group setting, but following the same topic guide. Participants in the group of informal carers of older adults consisted of one adult who cared for his parent, and six elderly residents of a sheltered housing scheme who were informal caregivers to each other. In the 'other' adults group, two first and second stage focus groups were held to accommodate the larger number of participants. Focus group/interview recordings ranged in duration from 34 to $69 \mathrm{~min}$. The majority of participants took part in both stages of data collection. Participant characteristics are summarised in table 1.

Participants revealed a wide range of experience, knowledge and levels of confidence in dealing with head injury. Descriptions of their confidence and willingness to act in response to a head injury were embedded within their general understandings of 'head injury'. It was apparent that the term held different meanings for individuals. For some, head injury always represented a serious situation, while others appreciated that it included a range from the minor to the severe. Common to all groups was the reasoning that head injury was more problematic than other injuries for two reasons: the potential seriousness of brain damage due to the vital role of the brain, and the fact that the damage may not be seen. Within this shared

Table 1 Participant characteristics

\begin{tabular}{|c|c|c|c|c|}
\hline Population group & Number of participants & Age group & Ethnicity (UK census categories) & Gender \\
\hline $\begin{array}{l}\text { Parents of young } \\
\text { children }\end{array}$ & $\begin{array}{l}\text { Stage } 1 \text { focus group: } 6 \\
\text { Stage } 2 \text { focus group: } 5 \\
\text { Total: } 8\end{array}$ & Not available & $\begin{array}{l}\text { Any other White background: } 3 \\
\text { White British: } 3 \\
\text { Black British: } 1 \\
\text { Mixed White and Black Caribbean: } 1\end{array}$ & Female: 8 \\
\hline $\begin{array}{l}\text { Informal carers of older } \\
\text { adults }\end{array}$ & $\begin{array}{l}\text { Stage } 1 \text { focus group: } 6 \\
\text { Stage } 2 \text { focus group: } 7 \\
\text { Total: } 7\end{array}$ & $\begin{array}{l}\text { 55-64: } 1 \\
75-84: 4 \\
85-94: 2\end{array}$ & White British: 7 & $\begin{array}{l}\text { Female: } 5 \\
\text { Male: } 2\end{array}$ \\
\hline Sports coaches & $\begin{array}{l}\text { Stage } 1 \text { interviews: } 2 \\
\text { Stage } 2 \text { interview: } 1 \\
\text { Total: } 2\end{array}$ & $\begin{array}{l}35-44: 1 \\
45-54: 1\end{array}$ & White British: 2 & $\begin{array}{l}\text { Female: } 1 \\
\text { Male: } 1\end{array}$ \\
\hline 'Other' adults & $\begin{array}{l}\text { Stage } 1 \text { focus group: } 10^{\star} \\
\text { Stage } 2 \text { focus group: } 11^{*} \\
\text { Total: } 11\end{array}$ & $\begin{array}{l}\text { 25-34: } 5 \\
35-44: 2 \\
45-54: 1 \\
55-64: 2 \\
75-84: 1\end{array}$ & $\begin{array}{l}\text { White British: } 4 \\
\text { Black Caribbean: } 2 \\
\text { Asian Chinese: } 1 \\
\text { Asian Indian: } 1 \\
\text { Any other Asian background: } 1 \\
\text { Any other White background: } 1 \\
\text { Black British: } 1\end{array}$ & Female: 11 \\
\hline
\end{tabular}

${ }^{*}$ In this population group, two focus groups were held at each stage to accommodate group size. 
perception of the potential seriousness of head injury, there was a wide range of knowledge and understanding-and sometimes misunderstanding - of clinical signs and symptoms, and what action to take as a first responder.

\section{Themes}

While participants within and across the six population groups were heterogeneous in their responses, several distinct patterns (themes) emerged from focus group discussions. Against the background of respondents' shared awareness of the potential seriousness of head injury, it was apparent that individuals' confidence and willingness to act were not static, but rather fluid and dependent on a multitude of situational and contextual considerations. These contingent factors were often considered before focusing on clinical signs and symptoms of head injury. They therefore presented a priori enablers-or, conversely, barriers-in influencing how participants thought they would behave in a head injury situation. Discussion of these considerations was very prevalent in focus groups-more so than discussion of implications of clinical signs and symptoms-and clearly impacted on participants' reasoning. It either altered their decision-making ('If context $\mathrm{A}$, then action X; but if context B, then action $\mathrm{Y}^{\prime}$ ) or added layers of complexity, which remained unresolved ('If context $\mathrm{A}$, then action $\mathrm{X}$; but if context B or C, I'm not sure'). Moreover, situational and contextual factors were often discussed in various combinations and scenarios, resulting in an interplay between enablers and barriers in addition to the clinical signs and symptoms displayed by the injured person. There was overlap in findings from the first and second stage of data collection, overall corroborating and reinforcing the themes developed in analysis:

- Prior knowledge and experience.

- Known or unknown injured person.

- Observed or unobserved injury taking place.

- Location and environment.

- Interplay of situational and contextual factors.

\section{Prior knowledge and experience}

The extent of prior knowledge and experience varied within and across population groups and appeared to be linked closely with individuals' levels of confidence and willingness to act as first responders. Some inaccuracies and misconceptions were noted, such as one participant's assumption that visible bruising was favourable, as lack of bruising could indicate 'a bleed on the inside' (F5, Parents of young children). Conversely, some participants displayed greater understanding of the role of medical diagnostics, for example referring to the need for a scan to detect whether there was an internal bleed. Among those with less prior knowledge and experience, some stated that they would panic:

F1: I'd panic because there's something about the word, head injury, that would make me panic actually. ('Other' adults)
Others explained that they would be more confident and willing to summon help than to provide advice or assistance in a more involved manner:

F2: Yes, maybe because I wouldn't know what to do, so instead of wasting time trying to figure out what to do, I'll just get someone who could help, keep it from getting worse. (Young adults)

In contrast, some participants who had completed more in-depth first aid training spoke confidently about what to do in a head injury situation. For example, two participants in the focus group with school staff held designated first aider roles at work and talked with confidence about the steps they would take if a pupil had been knocked unconscious for a few seconds:

F6: That's normally where we'd clear the area of other children and send someone down to the office, so that they can obviously make a phone call for an ambulance.

F8: Make sure the child stays lying on the floor. Doesn't sit up because they're very likely to go back over again. Check that they can still speak to us. They're coherent. They can breathe, and then wait to see what 999 [emergency ambulance call number] says we should do.

\section{(School staff)}

In these discussions participants mainly drew on prior knowledge from formal first aid training, but also talked about 'life experiences', for example from accounts or observations of head injury incidents at work or among family and friends:

M1: The experience you've had of life with bringing up a family and what you see at work, you see accidents at work and things like that, so you gain knowledge from each incident that you see. (Informal carers of older people)

\section{Known or unknown injured person}

In terms of characteristics of the injured person, knowing or not knowing the person appeared to be highly influential in how comfortable participants felt, as well as how willing they might be to act. Although this point was raised in all groups/interviews, it was particularly prominent in the groups with parents of young children and school staff. Participants talked about calling staff members who knew the child well, or calling parents to assess their own child. This appeared at times to be double-edged in that knowledge of the individual was considered vital to judge in how far the child 'behaved differently' following the head injury, but knowing the child brought an emotional component into play, particularly for parents, that they recognised impacted on their objective decision-making:

F5: If you looked after other people's children if they hit their head you'd be like, 'Right, we've got to let mum know. What do we do from there?' When it's 
your own kid you're kind of like, 'Do I go to hospital? Do I ring someone? Do I ring somebody?' (Parents of young children)

In general, participants discussed that they would respond in a more involved manner if they knew the injured person, for example escorting the person home if the injury had occurred outdoors, or accompanying them to hospital. A sense of belonging to the same group or community as the injured person also seemed to increase participants' willingness and confidence to be more involved:

F1: I think if also I can see similarities with that person in myself, I might be more willing to help as well. For example, I ride a bicycle, so if I saw a bike rider, I might respond quicker because I could be that person. ('Other' adults)

For a stranger, in contrast, participants appeared more likely to call an ambulance or give advice and then move on. Children and older people were generally considered more vulnerable, prompting greater caution and a lower threshold for using medical and emergency services. Several participants also considered how the injured person themselves might wish or intend to deal with the situation, provided they were conscious and able to express themselves:

F7: I think partly also, you'd be influenced by what they wanted to do. If they were really stressing out and they were like, 'Oh my God! My head's hurting' or, 'I feel like I'm going to pass out' you'd be like, 'Okay, you might need to go and get checked out.' If they were like, 'No, I'm fine,' I think it would influence your decision. ('Other' adults)

It was recognised that the injured person might not realise the seriousness of the situation, and at times one might have to act against someone's wishes for their own protection and the protection of others. Although not all participants would have been as confident as this sports coach:

Interviewer: It sounds like you would take it pretty seriously, you would sit them down, make them not get back on their bike.

F1: Yes, they're going to be a danger to other people, [...] the last thing you want is another [rider] out on the road again or on a racetrack or whatever it is, being a danger to other people. (Sports coaches)

\section{Observed or unobserved injury taking place}

Having witnessed the head injury, or noting the presence of a bruise, lump or bleeding head wound, which would indicate that the person has sustained a head injury, made a difference to participants' confidence and willingness to act. Participants considered that if the injury was unwitnessed, they might not feel as confident in their decisionmaking, because other medical conditions (stroke, seizure or heart attack) or alcohol and drug misuse might lead to similar symptoms:
F2: But that comes back to if you've seen them and you've seen they've had a blow to the head or an accident, I mean it could be a drunk, couldn't it? If they're behaving or speaking really differently, you just wouldn't know if you hadn't seen the accident.

('Other' adults)

In case of a witnessed head injury, several participants also talked about considering the mechanism of injury, for example the person hitting their head against concrete pavement as opposed to a door, or being hit by another person as opposed to bumping their head by accident. This observation could alter participants' perception of the potential injury severity and subsequent action taken:

F3: If they've been hit or something, then, yes, I would call an ambulance, but if it was a matter of them like hitting their head against a wall or something, like tripping over, then I wouldn't be inclined to. I think it depends on the situation and like their surroundings as well. (Young people)

\section{Location and environment}

Considerations around the location and environment, in which the head injury occurred, also influenced individuals' confidence and willingness to act. In an institutional setting, such as the university, young people for example talked of trying to find a first aider or other figure of authority, to help them decide what action was best in response to head injury. Similarly, the impact of a workplace environment was described by participants in the focus group with school staff and 'other' adults, who described following certain organisational rules for injury at work. Informal carers of older adults discussed that in a sheltered housing environment guidance was always to hand, either in person (warden) or via an alarm call. It was noted that this guidance was usually to contact medical advice.

The impact of institutional policies was most strongly and consistently reflected in the focus group with school staff. Here, a clear chain of communication was in operation; a junior member of school staff explained:

F4: Well, the procedure that we know is you get [first aider 1] or you get [first aider 2]. [...] We never make the final decision. We always pass it off. (School staff)

School staff understood organisational policy to streamline and facilitate their duty of care towards school children, but also considered its function in protecting school staff and the organisation. For example, they commented on the value of providing written information to parents of children who sustained a head injury at school, as this 'also covers the school'. Sports coaches also described a similar chain of communication at professional or largescale public sports events:

F1: If I came across somebody who had been involved in a head injury at one of our events, I always have a radio, so I would radio to event control and event control would then speak to our appointed medical 


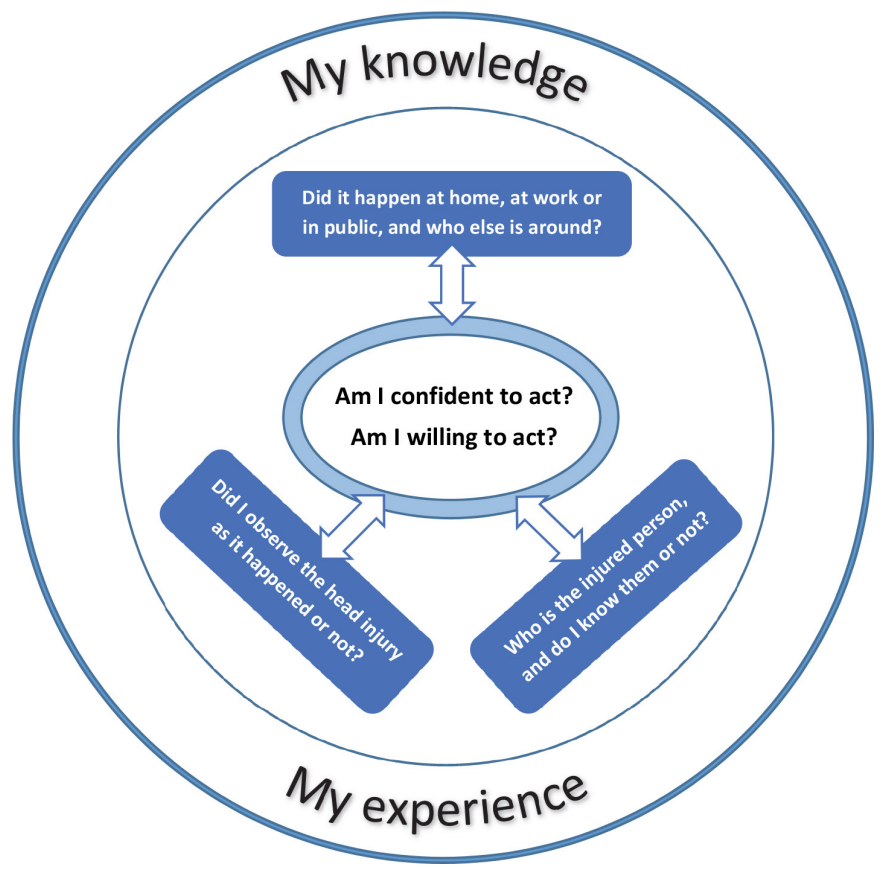

Figure 1 Individual conceptual model of confidence and willingness to act in a head injury situation. Against the background of individual knowledge and experience, situational and contextual factors have significant influence on the person's helping behaviour.

provider. [...] Depending on who it is, that help, that message would then be disseminated down through the channels. We have a medical director, so we have doctors as well as St. John and Red Cross. (Sports coaches)

But sports coaches also raised another issue they had encountered in an extreme sports environment, which related to a sense of pressure and expectation to continue on after an injury, rather than stop and recover:

M2: I notice that from a lot of people, it's almost like a sign of some kind of reward if you get up after really banging your head or hurting yourself. It's like you're some kind of warrior. (Sports coaches)

In contrast, some participants in other groups talked about taking a very cautious approach, and voiced their fear of doing something wrong and potential litigation, particularly in public and when dealing with a stranger:

F1: There's always that kind of thing where you want to help as a bystander, but at the same time you think so many people around you might be more qualified to do that, and you're like okay, I don't want to mess it up because it's the head! ('Other' adults)

\section{Interplay of situational and contextual factors}

These situational and contextual impacts on confidence and willingness to act were often discussed in combination and in layered scenarios. This prompted participants to think of additional contingent factors and appeared to create a situation of some concern for many participants, who might not have been overly alarmed about one of these factors in isolation. For example, participants commented on personal safety when considering a stranger in public following an unwitnessed head injury. This related to the potential danger of approaching a stranger who displays unusual behaviour, but also reluctance to provide hands-on assistance if blood were present. In this type of hypothetical scenario participants felt more comfortable to call for assistance rather than to get involved themselves. This became the underpinning concept to our analysis, i.e. participants described their confidence and willingness to act in relation to the situational and contextual factors of specific scenarios. Conceptually, these factors therefore represent an interplay of enablers and barriers, whereby prior knowledge and experience might be conceptualised as providing a backdrop to the situation-dependent aspects of known or unknown injured person, observed or unobserved injury, and location and environment. In addition these situational and contextual considerations, rather than the clinical signs and symptoms of head injury, had primary influence over lay responders' decision-making and helping behaviour. Figure 1 presents a visualisation of this in an individual conceptual model.

\section{DISCUSSION}

This study has explored laypersons' confidence and willingness to act as first responders in a head injury situation. In the majority, participants were willing to help if that meant calling for the assistance of someone else, but most did not feel confident or knowledgeable enough to either carry out physical intervention or observe and evaluate whether use of the ED could be avoided. Few participants felt confident to take charge of decision-making in a head injury situation. Participants raised multiple situational and contextual considerations, which impacted on their own confidence and willingness to act in a given situation. These factors may be framed as enablers and barriers, and include prior knowledge and experience, characteristics of the injured person, whether the injury was observed or unobserved, and the location and environment. While discussions within all six research population groups were wide-ranging and varied, there were some themes more prominent in certain groups, such as the impact of institutional policies and workplace practices in the groups with school staff and 'other' adults; and knowing or not knowing the child when judging behaviour following a head injury in the groups of parents with young children and school staff. The findings were summarised in an individual conceptual model (figure 1).

Study strengths and limitations relate to characteristics of the sample. The sample size was small, which is common in qualitative research that aims to generate in-depth findings for explanatory purposes. ${ }^{12}$ While there was under-recruitment of sports coaches, recruitment to the other five research population groups was successful. We recruited to the six population groups primarily to achieve thematic coverage, rather than for comparison between groups, but were nevertheless able to comment on themes more prevalent in certain groups. Diversity across sample demographics adds to the potential 
transferability and relevance of findings. It is acknowledged that, due to the snowball recruitment method, the sample was a self-selected group, likely with a personal interest in head injury and a desire to learn. We realise that the important issue of safeguarding, for example, with respect to child or elder abuse or neglect, was not a talking point in our focus groups. This may be due to discussions focusing on willingness to act rather than the circumstances of injury. We acknowledge that it may have been helpful to elicit discussion around safeguarding through specific prompts. Geographically, participants were based in the South East of England. Although the findings do not appear to closely relate to participants' location, it is possible that individuals from other regions in the UK-or internationally—would contribute additional or alternative views and experiences. A further strength of this study was the involvement of different project stakeholders, including representatives from the BRC, clinicians in National Health Service emergency services and service users. This added to the reflexive approach of the research team and the credibility of data and analysis.

The study concerned exploring confidence and willingness to act in head injury, as an assumed precursor to appropriate decision-making of laypersons in a head injury situation. This is topical in light of healthcare policy calling for a reduction in avoidable ED attendances and hospital admissions, ${ }^{16}{ }^{17}$ which our study viewed alongside the need to ensure that individuals with serious symptoms of head injury receive the prompt attention they require at the ED. Although some of our participants expressed a willingness to selfcare where first aid materials led them to believe this would be a safe option, our findings suggest that this would not be simple for all, or all of the time. Feeding into individuals' confidence and willingness to act in this way, the findings from this study suggest various situational and contextual considerations at play. These align with other literature on lay response and helping behaviour, ${ }^{18} 19$ which highlight problems due to lack of knowledge and experience, for example in identifying clinical symptoms and correct first aid measures in trauma, ${ }^{20}$ sports injury, ${ }^{21} 22$ heart attack, ${ }^{23}$ stroke ${ }^{24} 25$ and mental illness. ${ }^{26}$ Moreover, it has been suggested that in addition to individuals' knowledge and skills, the decision to act is dependent on acknowledgment of the situation and having confidence in one's own ability $^{18192728}$; and there is some evidence that first aid education needs to incorporate specific components to target positive attitudes and helping reactions towards emergencies (as opposed to factual knowledge and practical skills alone), in order to achieve improvements in helping behaviour. ${ }^{10}$ In contrast to cardiopulmonary resuscitation and other more involved and complex first aid scenarios, helping behaviour in head injury more often relates to observing the person and making decisions accordingly and should therefore be more easily amenable to interventions.
Most of the situational and contextual considerations identified in this study have also been recognised in other first aid settings. In the context of road traffic collisions, the following barriers to providing first aid have been described: not being a first aider, poor knowledge of the importance of providing first aid, fear of making a mistake, the scene feeling overwhelming, victim refusal, concern about infection, the presence of bleeding, not remembering the details of first aid and a concern about legal risk. ${ }^{28-30}$ In cardiopulmonary resuscitation, it was found that people were less likely to intervene with strangers than with family members, while enablers included first aid training and a controlled environment, particularly the person's own home. ${ }^{27}$ Interestingly, among the range of contingent factors identified in this study, the characteristics of the injured person, circumstances of the injury and the environment appeared to impact individuals' confidence to the same extent as-or even more than-their knowledge and experience. Consequently, in contrast to a medical assessment which focuses mainly on clinical signs and symptoms of head injury, these factors were highly influential to laypersons' decision-making often before clinical signs and symptoms were considered. This mirrors previous research, which has highlighted the role of psychological and emotional, rather than technical factors. ${ }^{18} 31$ Therefore, to achieve maximum impact, first aid education should not only convey factual knowledge but must also address contextual barriers to lay responders' confidence and willingness to act.

A recent evidence review by the International Liaison Committee on Resuscitation First Aid Task Force has highlighted the lack of scientific research into first aid education. ${ }^{32}$ This study has generated in-depth insights into behavioural enablers and barriers for laypersons to act as first responders in a head injury situation. These findings are relevant to inform educational interventions and public health campaigns on head injury, but may equally apply to first aid in general. The WHO recommends that health education should be underpinned by suitable behaviour change theories or models, a number of which are available. ${ }^{33}$ While the individual conceptual model presented here (figure 1) closely reflects the data in this study, it is possible to cross-reference to other commonly used behaviour change theories. For example in Social Cognitive Theory, ${ }^{35}$ self-efficacy (confidence in one's ability to take action and overcome barriers) and reciprocal determinism (the dynamic interaction of the person, their behaviour and the environment) constitute key concepts, ${ }^{33}$ which shows distinct parallels and relevance to the data in this study. Future research could develop tools to quantify the impact of different situational and contextual factors on helping behaviour, as research instruments or to facilitate individual learning, particularly impact on faster provision of first aid alongside greater self-care where appropriate. The findings of this study may therefore inform the future development, implementation and evaluation of targeted health education interventions for laypersons responding to a head injury. There also remains scope for further work to 
address study limitations and explore these issues in groups and regions that were under-represented in this research.

\section{Twitter Emily Oliver @emilyoliver143}

Acknowledgements We thank service user advisors Elizabeth Lloyd-Dehler and Nicholas Low for their valuable feedback and suggestions on the study design. We thank Michael Fanner for his contributions to study design and data collection. This study was overseen by a British Red Cross steering committee consisting of Dr Barry Klaassen, Dr James Robson, Joe Mulligan, Dawn Sheppard, Tracey Taylor, Lucy Ellis, Alexander Ward and Emily Oliver.

Contributors $\mathrm{MH}$ is chief investigator for this study. MH, AH, SG, BK, EO and HJ designed the study. MH, AB, STK and AH collected and analysed the data. All coauthors contributed to the interpretation of the data. STK prepared the manuscript. E0 supported the writing and coordinated input from the British Red Cross study steering group led by BK. All co-authors critically reviewed and approved the final manuscript.

Funding This research was funded by the British Red Cross which received funding from Elastoplast for their larger programme of work on first aid education and training in head injury.

Competing interests $\mathrm{MH}$ reports grants from British Red Cross during the conduct of the study. BK reports grants from Elastoplast during the conduct of the study. EO reports grants from Elastoplast during the conduct of the study and outside the submitted work. E0 reports the British Red Cross commissioned this study in the context of developing a lay responder pathway to head injuries. The British Red Cross is a first aid education provider and standard setter.

\section{Patient consent for publication Not required.}

Ethics approval The study was approved by the Faculty Research Ethics Committee of the Faculty of Health, Social Care and Education at Kingston University and St George's, University of London (FREC 2017-12-014).

Provenance and peer review Not commissioned; externally peer reviewed. Data availability statement № data are available.

Open access This is an open access article distributed in accordance with the Creative Commons Attribution Non Commercial (CC BY-NC 4.0) license, which permits others to distribute, remix, adapt, build upon this work non-commercially, and license their derivative works on different terms, provided the original work is properly cited, appropriate credit is given, any changes made indicated, and the use is non-commercial. See: http://creativecommons.org/licenses/by-nc/4.0/.

\section{ORCID iDs}

Stefan Tino Kulnik http://orcid.org/0000-0001-5419-6713

Emily Oliver http://orcid.org/0000-0003-0087-3285

\section{REFERENCES}

1 NICE. Head Injury: Assessment and Early Management Clinical Guideline [cg176] January 2014 last updated: June 2017. 2017 [internet]. Available: https://www.nice.org.uk/guidance/cg176/ chapter/1-recommendations\#pre-hospital-assessment-advice-andreferral-to-hospital [Accessed 19 Nov 2018].

2 Ismail SA, Gibbons DC, Gnani S. Reducing inappropriate accident and emergency department attendances: a systematic review of primary care service interventions. Br J Gen Pract 2013;63:e813-20.

3 NHS Health A-Z. Head injury and concussion, 2018. Available: https://www.nhs.uk/conditions/minor-head-injury/ [Accessed 19 Nov 2018].

4 Oliver GJ, Walter DP, Redmond AD. Are prehospital deaths from trauma and accidental injury preventable? a direct historical comparison to assess what has changed in two decades. Injury 2017;48:978-84

5 McNulty A. Are prehospital deaths from trauma and accidental injury preventable? A summary report. London: British Red Cross, 2016.

6 Vaillancourt C, Stiell IG, Wells GA. Understanding and improving low bystander CPR rates: a systematic review of the literature. CJEM 2008;10:51-65.

7 Faul M, Aikman SN, Sasser SM. Bystander intervention prior to the arrival of emergency medical services: comparing assistance across types of medical emergencies. Prehosp Emerg Care 2016;20:317-23.
8 Fischer P, Krueger Jl, Greitemeyer T, et al. The bystander-effect: a meta-analytic review on bystander intervention in dangerous and non-dangerous emergencies. Psychol Bull 2011;137:517-37.

9 Oliver E, Cooper J, McKinney D. Can first aid training encourage individuals' propensity to act in an emergency situation? A pilot study. Emerg Med J 2014;31:518-20.

10 Van de Velde S, Heselmans A, Roex A, et al. Effectiveness of nonresuscitative first aid training in laypersons: a systematic review. Ann Emerg Med 2009;54:447-57.

11 Powell RA, Single HM, Lloyd KR. Focus groups in mental health research: enhancing the validity of user and provider questionnaires. Int J Soc Psychiatry 1996;42:193-206.

12 Creswell J. Research design: qualitative and quantitative approaches. Thousand Oaks, CA: Sage, 1994.

13 Tashakkori A, Teddlie C. Handbook of mixed methods in social and behavioral research. 2nd ed. Thousand Oaks, CA: Sage, 2010.

14 Greene J. Mixed methods in social inquiry. San Francisco, CA: Jossey-Bass, 2007.

15 Gale NK, Heath G, Cameron E, et al. Using the framework method for the analysis of qualitative data in multi-disciplinary health research. BMC Med Res Methodol 2013;13:117.

16 NHS. The NHS long term plan, 2019. Available: https://www. longtermplan.nhs.uk/publication/nhs-long-term-plan/ [Accessed 12 Feb 2019].

17 National Audit Office. Reducing emergency admissions. London: National Audit Office, 2018.

18 Eisenburger P, Safar P. Life supporting first aid training of the public-review and recommendations. Resuscitation 1999;41:3-18.

19 Miller B, Pellegrino JL. Measuring intent to aid of lay responders: survey development and validation. Health Educ Behav 2018:45:730-40.

20 Tannvik TD, Bakke HK, Wisborg T. A systematic literature review on first aid provided by laypeople to trauma victims. Acta Anaesthesiol Scand 2012;56:1222-7.

21 Abernethy Let al. Immediate care of school sport injury. Injury Prevention 2003:9:270-3.

22 Kaut KP, DePompei R, Kerr J, et al. Reports of head injury and symptom knowledge among college athletes: implications for assessment and educational intervention. Clin J Sport Med 2003;13:213-21.

23 Zapka JG, Oakes JM, Simons-Morton DG, et al. Missed opportunities to impact fast response to AMI symptoms. Patient Educ Couns 2000;40:67-82.

24 Alberts MJ. Improving public education about stroke. Ann N Y Acad Sci 2012;1268:45-50.

25 Gibson JME, Bullock M, Ford GA, et al. 'Is he awake?': dialogues between callers and call handlers about consciousness during emergency calls for suspected acute stroke. Emerg Med $\mathrm{J}$ 2013;30:414-8

26 Erritty P, Wydell TN. Are lay people good at recognising the symptoms of schizophrenia? PLoS One 2013;8:e52913.

27 Huang Q, Hu C, Mao J. Are Chinese students willing to learn and perform bystander cardiopulmonary resuscitation? J Emerg Med 2016;51:712-20.

28 Axelsson A. Bystander cardiopulmonary resuscitation: would they do it again? J Cardiovasc Nurs 2001;16:15-20.

29 Arbon P, Hayes J, Woodman R. First aid and harm minimization for victims of road trauma: a population study. Prehosp Disaster Med 2011;26:276-82.

30 Mabbott N. Harm minimisation for victims of road trauma at the pre-ambulance attendance phase. Road Safety Research, Policing \& Education Conference 26-28 November 2000. Brisbane, Australia. Available: https://acrs.org.au/files/arsrpe/RS000007.pdf

31 Booker MJ, Purdy S, Shaw ARG. Seeking ambulance treatment for 'primary care' problems: a qualitative systematic review of patient, carer and professional perspectives. BMJ Open 2017;7:e016832.

32 Singletary EM, Zideman DA, De Buck EDJ, et al. Part 9: first aid: 2015 international consensus on first aid science with treatment recommendations. Circulation 2015;132:S269-311.

33 World Health Organization. Health education: theoretical concepts, effective strategies and core competencies. Cairo: Regional Office for the Eastern Mediterranean Region, 2012.

34 Davis R, Campbell R, Hildon Z, et al. Theories of behaviour and behaviour change across the social and behavioural sciences: a scoping review. Health Psychol Rev 2015;9:323-44.

35 Bandura A. Self-Efficacy. The exercise of control. New York: W.H: Freeman and Company, 2002. 